\title{
The Association between Daily Fluid Balance and Mean Perfusion Pressure as a Critical Sign in the Intensive Care Unit of Adam Malik Central Hospital, Medan
}

\author{
Bastian Lubis ${ }^{1,2 *}$ (D) , Putri Amelia ${ }^{3,4}$ D , Muhammad Akil Yerilwan Putra ${ }^{1 *}$ (D) \\ ${ }^{1}$ Department of Anesthesiology, Faculty of Medicine, Universitas Sumatera Utara, Medan, Indonesia; ${ }^{2}$ Functional Medical Unit \\ of Anesthesiology, H. Adam Malik Central Hospital, Medan, Indonesia; ${ }^{3}$ Department of Child Health, Faculty of Medicine, \\ Universitas Sumatera Utara, Medan, Indonesia; ${ }^{4}$ Functional Medical Unit of Child Health, H. Adam Malik Central Hospital, \\ Medan, Indonesia
}

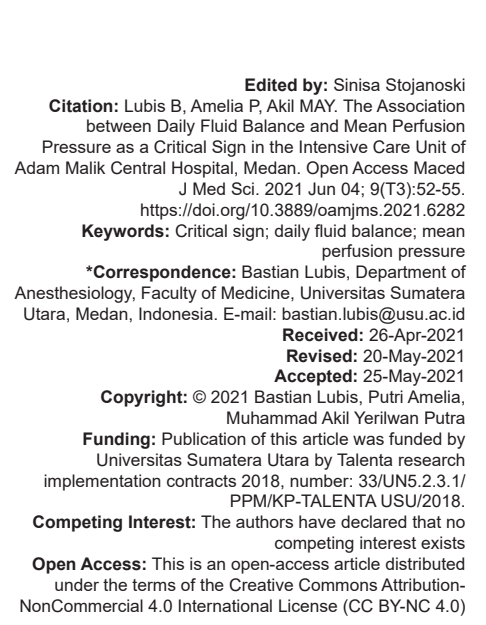

\section{Abstract}

BACKGROUND: The patient mortality rate in intensive care unit (ICU) is still high. However, we still lack measures to reduce this high mortality rate. Fluid balance is known as a marker for mortality in ICU. If the balance of fluid becomes more positive, the mortality rate consequently becomes higher. Positive fluid balance elevates central venous pressure (CVP), while this elevation increases the risk of renal failure and mortality. Mean perfusion pressure (MPP) is the difference between mean arterial pressure and CVP.

AIM: We propose that the MPP value can be used as an alternative indicator to monitor excessive fluid balance since its measurement is faster and more accurate than the manual $24 \mathrm{~h}$ record of fluid balance.

PATIENTS AND METHODS: It is expected that we can prevent excessive fluid accumulation and the subsequent mortality risk by monitoring MPP in the ICU. To investigate the association between MPP and daily fluid balance in the ICU, a prospective study was conducted from March 2016 to August 2018 in the ICU of Adam Malik Hospital, Medan. During the study period, 76 patients were admitted. Sixty-point $5 \%$ were male, with the mean age of $48.3 \pm$ 16.5 years old.

RESULTS: The overall mortality of 76 patients was $10.5 \%$, and there was a significant negative correlation found between MPP and fluid balance $(r=-0.204 ; p=0.048)$, where a lower MPP value was associated with a more positive fluid balance.

CONCLUSIONS: We conclude that there is a negative correlation between MPP and fluid balance, where a more positive fluid balance is associated with a lower MPP value. The positive fluid balance had been previously associated with increased mortality risk in the ICU.

\section{Background}

In patients with a critical condition, fluid balance is one of the important factors to be maintained [1], [2]. Daily fluid balance is the difference between all intakes and outputs [3], [4]. Fluid balance is a part of the process of care [3], [4], [5]. Proper management of fluid balance can treat hypotension, sepsis, heart failure, and acute kidney injury (AKI) [2], [3].

However, cumulative fluid accumulation is recognized as a potential threat that can increase morbidity and mortality [3], [6], [7]. Positive fluid balance elevates central venous pressure (CVP) and increases mortality in septic patients [6]. It also has negative impacts in critically ill patients with acute renal injury, for the positive fluid balance is known to impede renal recovery [8].

It is widely known that CVP is a traditional indicator frequently monitored in the intensive care unit (ICU). The research found that the higher value of CVP is associated with worse outcomes [9]. Meanwhile, in patients who underwent cardiac surgery, it is understood that CVP may be useful for determining mortality and risk for renal failure [10]. Central venous uptake is also often associated with renal impairment and death [11].

Meanwhile, mean perfusion pressure (MPP) is the difference between mean arterial pressure (MAP) and CVP [12]. The difference between these pressures is related to the patient's mortality rate in the ICU. Furthermore, patients with low MPP are found to have high rates of renal failure [13].

To prevent $\mathrm{AKI}$ and reduce mortality in treating patients with fluid therapy, it is understood that we need to maintain adequacy and to avoid excessively positive balance. We propose that the MPP value can be used as an alternative indicator to monitor excessive fluid balance since its measurement is faster and more accurate than the manual $24 \mathrm{~h}$ record of fluid balance. It is expected that we can prevent excessive fluid accumulation and the subsequent mortality risk by monitoring MPP. This study aims to investigate the 
association between MPP, daily fluid balance, and mortality in the ICU.

\section{Methods}

This cohort study was conducted from March 2016 to August 2018 in the ICU of Adam Malik Hospital, Medan. The sampling method was consecutive sampling. Patients with age over 18 years admitted to our ICU during the study period were included in the study. Informed consent was given to confirm the willingness to participate. Patients who refuse to be involved in the study were excluded from the study.

The demographic data, MAP, CVP, MPP, and cumulative fluid balance were analyzed to investigate the association between MPP and daily fluid balance, and mortality in the ICU. MPP was measured by calculating the difference between MAP and CVP. MAP was observed using the ICU monitor, while CVP was measured manually through a central venous catheter.

Data were analyzed using SPSS version 26.0. The quantitative variable was expressed as means and standard deviations. The categorical variables were described by their absolute $(n)$ and relative (\%) frequencies. Pearson's correlation test was used to analyze for an association between daily fluid balance and MPP. $p<0.05$ was considered statistically significant. This study was approved by the Ethics Committee of Faculty of Medicine, Universitas Sumatera Utara.

\section{Results}

During the study period, 76 patients were admitted. About $60.5 \%$ were male, and $39.5 \%$ were female. The mean age of patients admitted was 48.3 \pm 16.5 years old. Eight patients died during the study with the overall mortality of $10.5 \%$, predominantly male (Table 1).

Table 1: Patients characteristics

\begin{tabular}{ll}
\hline Variables & $\mathrm{n}(\%) /$ Mean (SD) \\
\hline Mean age (SD), years & $48.3(16.5)$ \\
Gender, $\mathrm{n}(\%)$ & \\
$\quad$ Male & $45(60.5)$ \\
$\quad$ Female & $31(39.5)$ \\
Mean MPP (SD), mmHg & $86.9(18.04)$ \\
Mean cumulative fluid balance (SD), cc & $-10.2(829.5)$ \\
Mortality, n (\%) & \\
Yes & $8(10.5)$ \\
No & $68(89.5)$ \\
\hline
\end{tabular}

There was a significant negative correlation found between MPP and fluid balance $(r=-0.204 ; p=$ $0.048)$, where a lower MPP value was associated with a more positive fluid balance (Table 2 ).
Table 2: Association between MPP and cumulative fluid balance

\begin{tabular}{lll}
\hline MPP & MPP & Balance \\
\hline Pearson correlation $(r)$ & 1 & -0.204 \\
Sig. (two tailed) & 76 & 0.048 \\
$\mathrm{n}$ & & 76 \\
\hline Balance & -0.204 & 1 \\
\hline Pearson correlation $(r)$ & 0.048 & 76 \\
Sig. (two tailed) & 76 & \\
$\mathrm{n}$ & & \\
\hline
\end{tabular}

\section{Discussion}

This study found that there is a significant negative correlation between MPP and fluid balance. This finding will be useful in monitoring the ICU patients since MPP measurement is faster and more reliable than the manual record of fluid balance, which is very prone to mistakes. Our study found that a lower MPP was associated with a more positive fluid balance, which is in line with research by Patel et al. [12].

The higher fluid balance associated with an increase in mortality and possibly reduced renal recovery [5], [14], [15], [16]. Eight patients died during the study period which represented $10.5 \%$ of the study population, while other studies showed varied results, ranging from $15 \%$ to $58 \%$ [5], [12], [13], [14], [15], [16], [17]. Most of them had low MPP and positive fluid balance (Table 3 ). The mean age of patients was 43 years old. The value was different from other studies, which mostly above 60 years old [5], [12], [13], [14], [15], [16], [17]. The gender mostly admitted to ICU was male for $60.5 \%$. Bouchard et al., Patel et al., and Ostermann et al. also had relatively the same percentage of male dominance.

Table 3: Non-survivor characteristics

\begin{tabular}{lllll}
\hline Dead & MPP & Balance & Age & Sex \\
\hline 1 & 54.80 & 1334.00 & 73 & Male \\
2 & 47.60 & 423.00 & 55 & Male \\
3 & 52.40 & 646.00 & 22 & Male \\
4 & 41.90 & 1391.00 & 27 & Male \\
5 & 54.80 & 206.40 & 65 & Male \\
6 & 73.00 & 419.00 & 21 & Male \\
7 & 54.90 & -2376.00 & 69 & Male \\
8 & 39.10 & 300.00 & 80 & Female \\
\hline
\end{tabular}

Increasing CVP had a more significant impact on AKI progression than MAP [12], [13], [17]. AKI was one of the main problems in ICU, and the mortality rate was high. Because of the high mortality, early detection and prevention were needed [8], [18]. Fluid balance was one of the important markers for AKI beside creatinine serum. MPP is also a potential marker for AKI [17]. By measuring CVP and MAP, we can calculate MPP (CVP-MAP). CVP represents congestion in vena, and MAP represents renal perfusion. Using these variables, we can predict AKI occurrence [13]. It is expected that we can prevent excessive fluid accumulation and the subsequent mortality risk by monitoring MPP, which will enable a prompt intervention for patients at risk in the ICU. 
There were some limitations in our study. We had a relatively small sample size, and the research was conducted in a single center, which may have led to bias due to specific environmental characteristics in the population.

\section{Conclusions}

In this study, we conclude that there is a negative correlation between MPP and fluid balance, where a more positive fluid balance is associated with a lower MPP value. The positive fluid balance had been previously associated with increased mortality risk in the ICU.

\section{Declarations}

This study was approved by the Ethics Committee of the Faculty of Medicine, Universitas Sumatera Utara. Informed consent for participation was obtained before the research was conducted.

\section{Authors' Contributions}

$B L, P A$, and MA wrote the manuscript and designed the experiments. BL and PA performed the experiments. BL and MA performed the data analysis. $\mathrm{BL}$ and PA performed the statistical testing. All authors read and approved the final manuscript.

\section{Acknowledgments}

We thank Universitas Sumatera Utara by Talenta research, which funded and supported this study to be published, and $\mathrm{H}$. Adam Malik Central Hospital for providing the research facilities.

\section{Availability of Data and Materials}

All data analyzed for this paper are available from the corresponding authors on reasonable request.

\section{References}

1. Silversides JA, Pinto $R$, Kuint $R$, Wald $R$, Hladunewich MA, Lapinsky SE, et al. Fluid balance, intradialytic hypotension, and outcomes in critically ill patients undergoing renal replacement therapy: A cohort study. Crit Care. 2014;18(6):624. https://doi. org/10.1186/s13054-014-0624-8

PMid:25407408

2. Perren A, Markmann M, Merlani G, Marone C, Merlani P. Fluid balance in critically ill patients. Should we really rely on it? Minerva Anestesiol. 2011;77(8):802-11.

PMid:21730928

3. Malbrain ML, Marik PE, Witters I, Cordemans C, Kirkpatrick AW, Roberts DJ, et al. Fluid overload, de-resuscitation, and outcomes in critically ill or injured patients: A systematic review with suggestions for clinical practice. Anaesthesiol Intensive Ther. 2014;46(5):361-80. https://doi.org/10.5603/ait.2014.0060 PMid:25432556

4. Kelm DJ, Perrin JT, Cartin-Ceba R, Gajic O, Schenck L, Kennedy CC. Fluid overload in patients with severe sepsis and septic shock treated with early goal-directed therapy is associated with increased acute need for fluid-related medical interventions and hospital death. Shock. 2015;43(1):68-73. https://doi.org/10.1097/shk.0000000000000268

PMid:25247784

5. Goldstein S, Bagshaw S, Cecconi M, Okusa M, Wang H, Kellum J, et al. Pharmacological management of fluid overload. Br J Anaesth. 2014;113(5):756-63. https://doi.org/10.1093/bja/ aeu299 PMid:25209097

6. Boyd JH, Forbes J, Nakada TA, Walley KR, Russell JA. Fluid resuscitation in septic shock: A positive fluid balance and elevated central venous pressure are associated with increased mortality. Crit Care Med. 2011;39(2):25965. https:// doi.org/10.1097/ccm.0b013e3181feeb15 PMid:20975548

7. Cordemans C, de Laet I, van Regenmortel N, Schoonheydt K, Dits $\mathrm{H}$, Malbrain ML, etal. Fluid management in critically ill patients: The role of extravascular lung water, Abdominal hypertension, Capillary leak, And fluid balance. Ann Intensive Care. 2012;2012 Suppl 1:S1. https://doi.org/10.1186/2110-5820-2-s1-s1 PMid:22873410

8. Bouchard JE, Mehta RL. Fluid balance issues in the critically II patient. Contrib Nephrol. 2010;164:69-78. PMid:20427995

9. Long Y, Su L, Zhang Q, Zhou X, Wang H, Cui N, et al. Elevated mean airway pressure and central venous pressure in the first day of mechanical ventilation indicated poor outcome. Crit Care Med. 2017;45(5):e485-92. https://doi.org/10.1097/ ccm.0000000000002290

PMid:28244940

10. Williams JB, Peterson ED, Wojdyla D, Harskamp $R$, Southerland KW, Ferguson TB, et al. Central venous pressure after coronary artery bypass surgery: Does it predict postoperative mortality or renal failure? J Crit Care. 2014;29(6):1006-10. https://doi.org/10.1016/j.jcrc.2014.05.027 PMid:25035048

11. Damman K, van Deursen VM, Navis G, Voors AA, van Veldhuisen DJ, Hillege HL. Increased central venous pressure is associated with impaired renal function and mortality in a broad spectrum of patients with cardiovascular disease. J Am Coll Cardiol. 2009;53(7):582-8. https://doi.org/10.1016/j. jacc.2008.08.080

PMid:19215832 
12. Patel R, Solanki A, Patel H, Pandya H, Patel J, Patel S. Does mean perfusion pressure during cardiopulmonary bypass affect renal function? J Evid Based Med Healthc. 2015;2(41):6946-53. https://doi.org/10.18410/jebmh/2015/948

13. Ostermann M, Hall A, Crichton S. Low mean perfusion pressure is a risk factor for progression of acute kidney injury in critically ill patients-a retrospective analysis. BMC Nephrol. 2017;18(1):151. https://doi.org/10.1186/s12882-017-0568-8

PMid:28468613

14. Payen D, de Pont AC, Sakr Y, Spies C, Reinhart K, Vincent JL. A positive fluid balance is associated with a worse outcome in patients with acute renal failure. Crit Care. 2008;12(3):R74. https://doi.org/10.1186/cc6916 PMid:18533029

15. Bouchard J, Soroko SB, Chertow GM, Himmelfarb J, Ikizler TA, Paganini EP, et al. Fluid accumulation, survival and recovery of kidney function in critically ill patients with acute kidney injury. Kidney Int. 2009;76(4):422-7. https://doi.org/10.1038/

\section{ki.2009.159 \\ PMid: 19436332}

16. Wang $N$, Jiang $L$, Zhu $B$, Wen $Y, X i X M$. Fluid balance and mortality in critically ill patients with acute kidney injury: A multicenter prospective epidemiological study. Crit Care. 2015;19(1):371. https://doi.org/10.1186/s13054-015-1085-4 PMid:26494153

17. Panwar R, Lanyon N, Davies AR, Bailey M, Pilcher D, Bellomo R. Mean perfusion pressure deficit during the initial management of shock-an observational cohort study. J Crit Care. 2013;28(5):816-24. https://doi.org/10.1016/j.jcrc.2013.05.009 PMid:23849541

18. Bagshaw SM, Brophy PD, Cruz D, Ronco C. Fluid balance as a biomarker: Impact of fluid overload on outcome in critically ill patients with acute kidney injury. Crit Care. 2008;12(4):169. https://doi.org/10.1186/cc6948

PMid:18671831 